\title{
Engraved bones from the archaic hominin site of Lingjing, Henan Province
}

\author{
Zhanyang $\mathrm{Li}^{1,2}$, Luc Doyon ${ }^{1,3}$, Hao $\mathrm{Li}^{4,5}$, Qiang Wang ${ }^{1}$, \\ Zhongqiang Zhang ${ }^{1}$, Qingpo Zhao ${ }^{1,2} \&$ Francesco d'Errico ${ }^{3,6, *}$
}

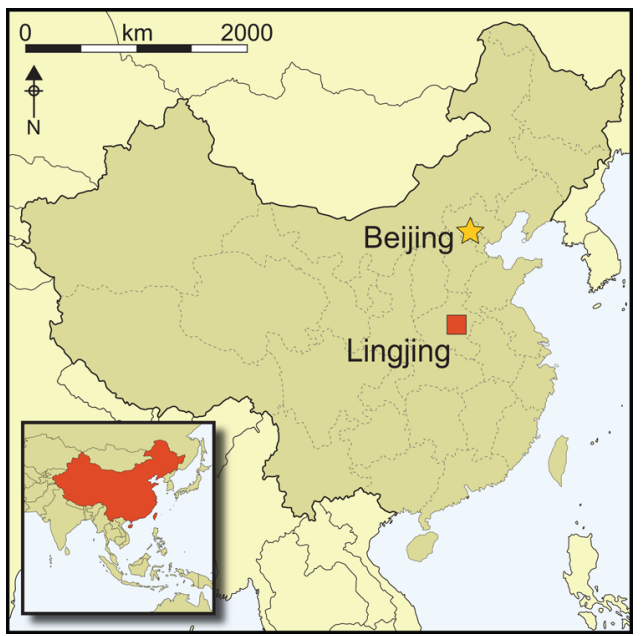

The production of abstract engravings is considered an indicator of modern human cognition and a means for the long-term recording and transmission of information. This article reports the discovery of two engraved bones from the Lingjing site in Henan Province, China, dated to 105-125 kya. The carefully engraved nature of the incisions, made on weathered rib fragments, precludes the possibility of unintentional or utilitarian origins. Residue analysis demonstrates the presence of ochre within the incised lines on one specimen. This research provides the first evidence for the deliberate use of ochred engravings for symbolic purposes by East Asian Late Pleistocene hominins.

Keywords: East Asia, China, Late Pleistocene, symbolism, art, ochre

\section{Introduction}

Opinions differ between those who consider archaic hominin cognition to be comparable to that of anatomically modern humans (e.g. Hovers \& Belfer-Cohen 2006; Nowell 2010;

1 Institute of Cultural Heritage, Shandong University, 27 Shanda Nanlu, Hongjialou District, Jinan 250100, P.R. China

2 Henan Provincial Institute of Cultural Relics and Archaeology, 93 ${ }^{\text {rd }}$ Street North, LongHai Road, Guancheng District, Zhenzhou 450000, P.R. China

3 Centre National de la Recherche Scientifique, UMR 5199-PACEA, Université de Bordeaux, Bâtiment B2, Allée Geoffroy Saint Hilaire, CS 50023, 33615 Pessac CEDEX, France

4 Key Laboratory of Vertebrate Evolution and Human Origins, Institute of Vertebrate Paleontology and Paleoanthropology, Chinese Academy of Sciences, 142 Xizhimenwai Street, Xicheng District, Beijing 100044, P.R. China

5 CAS Center for Excellence in Life and Paleoenvironment, 142 Xizhimenwai Street, Xicheng District, Beijing 100044, P.R. China

6 SFF Centre for Early Sapiens Behaviour (SapienCE), University of Bergen, Øysteinsgate 3, Postboks 7805, 5020, Bergen, Norway

* Author for correspondence (Email: francesco.derrico@u-bordeaux.fr) 
d'Errico \& Stringer 2011; Zilhão 2011; Villa \& Roebroeks 2014), and those who consider morphological, physiological, ontogenetic and behavioural differences to suggest different cognitive frameworks (e.g. Spoor et al. 2003; Lieberman 2007; Gunz et al. 2010; Junker 2010; Mellars 2010; Benazzi et al. 2011; de Boer 2012; Pearce et al. 2013; Bruner 2014; Neubauer 2015). The first viewpoint is supported by the fact that the emergence of our species in Africa, c. $300 \mathrm{kya}$ (Grün et al. 1996; Stringer 2016; Hublin et al. 2017), was not accompanied by the immediate development of behaviours characteristic of historically documented populations. For tens of thousands of years after their emergence, anatomically modern human populations in Africa continued to use technologies that differed little from those of the non-modern populations preceding them, or from those contemporaneous populations inhabiting other regions, both inside and outside the African continent. It is also supported by the discovery of cultural innovations generally considered to be hallmarks of modern cognition among archaic populations of Eurasia. Burials, the collection of fossils and other rare objects, the production of personal ornaments and engraved patterns, pigment use, cave painting and the extraction of bird feathers and claws are all interpreted as proof that Neanderthals in Europe and the Near East engaged in symbolically mediated behaviour (e.g. Pettitt 2002; Zilhão et al. 2010; Peresani et al. 2011; Finlayson et al. 2012; Rodríguez-Vidal et al. 2014; Romandini et al. 2014; Radovčí et al. 2015; Hoffmann et al. 2018). Most of these innovative cultural adaptations, however, are virtually unknown in vast regions inhabited by archaic hominins prior to the arrival of modern human populations-particularly in East Asia. A putative engraving on a bone flake from the Shiyu site, Shanxi Province, dated to 32-28 kya (You 1984), has been interpreted as resulting from post-depositional surface modifications (Bednarick 1994).

Abstract engravings are reported from almost 40 African and Eurasian sites dated prior to $40 \mathrm{kya}$ (see online supplementary material (OSM) 1). The earliest examples are the engraved patterns on a freshwater shell from Trinil, Indonesia, dating to $540 \mathrm{kya}$; a bone from Bilzingsleben in Germany (370 kya; see, however, Müller \& Pasda 2011), ochre fragments from the South African sites of Klasies River, Pinnacle Point and Blombos Cave (110-73 kya); and an antler from Vaufrey in France, dating to 120 kya (Vincent 1988; Henshilwood et al. 2009; Watts 2010; d'Errico et al. 2012). In China, engraved objects from Pleistocene contexts are rare. The earliest possible example is a Stegodon ivory tusk found in a layer dated to 150-120 kya at Xinglongdong Cave, south China. The piece displays a few longitudinal incisions close to the tip of the tusk. Both the site's chronology and the anthropogenic nature of the incisions have been questioned, as elephants use their tusks for a variety of activities that could result in their breakage or the development of ground facets and incisions (Haynes 1991; Villa \& d'Errico 2001; Norton \& Jin 2009). Elsewhere, a pebble from a context dated to $c$. 40 kya from the lower cultural unit of Shuidonggou locality 1 exhibits a set of sub-parallel and intersecting lines (Peng et al. 2012). Pei (1934) describes an engraved antler from Zhoukoudian Upper Cave, now dated to 34-29 kya (Chen et al. 1992). A putative engraved bone flake recovered from the Shiyu site, Shanxi Province, dated to 32-28 kya (You 1984) has been questioned on the basis of postdepositional surface modifications (Bednarik 1994). Finally, an antler fragment with an engraved pattern comprising sinuous parallel lines is reported from Longgu Cave, Hebei Province, dated to 13 kya (Bednarik \& You 1991). 
Here, we report the discovery of weathered bone fragments exhibiting deliberately engraved lines, one of which is filled with ochre, found at the 125-105 kya site of Lingjing in China. The fragments were found in the same stratigraphic layer that yielded hominin remains attributed to an archaic population exhibiting a mosaic of anatomical features suggestive of complex population dynamics between Eastern and Western Eurasia (Li et al. 2017). Recently, it has been suggested that the Lingjing hominins were Denisovans (Martinón-Torres et al. 2017: 444), although there is currently insufficient palaeogenetic evidence to corroborate this hypothesis.

\section{Archaeological context}

Lingjing ( $34^{\circ} 04^{\prime} 08.6^{\prime \prime}$ north, $113^{\circ} 40^{\prime} 47.5^{\prime \prime}$ east; $117 \mathrm{~m}$ asl) is an open-air site located in Henan Province, northern China, approximately $120 \mathrm{~km}$ south of the Yellow River (Figure 1). The site was discovered in 1965. Since 2005, excavations under the supervision of the first author have uncovered $551 \mathrm{~m}^{2}$ of the site. The $9 \mathrm{~m}$-deep, water-lain sedimentary sequence comprises 11 geological layers (for details, see OSM 2). Three main archaeological horizons attest to human occupation of the site during the Holocene (layers 1-4), the Late Glacial Maximum to the Younger Dryas (layer 5), and the early Late Pleistocene (layers 10-11). Optically stimulated luminescence (OSL) dates from layer 11 indicate that deposition took place $c$. 125-105 kya (Nian et al. 2009), during the early phases of Marine Isotope Stage 5. The faunal assemblage from layer 11 is dominated by horse (Equus caballus), onager (Equus hemionus) and auroch (Bos primigenius). Skeletal elements from late Middle and early Late Pleistocene fauna were also identified in this layer (Li \& Dong 2007). The high proportion of limb elements ( $>60$ per cent) and high frequency of cut marks observed on midshafts (approximately 34 per cent) suggest that Lingjing layer 11 was a kill-butchery site (Zhang et al. 2012).

The lithic assemblage from layer 11 comprises mostly quartz and quartzite artefacts. The presence of cores, flakes, formal tools and debris, plus the identification of use wear on some artefacts ( $\mathrm{Li}$ 2007; Li et al. 2019), of bone retouchers, organic soft hammer and pressure flakers (Doyon et al. 2018, 2019), suggest that knapping activities, including tool manufacture and use, occurred at the site. The two engraved bone fragments described in this study also derive from layer 11. Discovered in 2009, their engravings were later identified during analysis of the faunal assemblage conducted in 2016.

\section{Methods}

Excavation methods at Linging involved the careful removal of sediments using curvedtipped trowels to avoid damaging finds, the 3D plotting of bone remains and lithic artefacts, and sediment sieving through $2 \mathrm{~mm}$ mesh. Lithic and faunal remains are cleaned using soft brushes under running water. When present, sediment concretions are not removed from the faunal remains.

The artefacts described in this study are curated at the Henan Provincial Institute for Cultural Relics and Archaeology, Zhengzhou, China. Permission was granted to analyse one object (9L0141) at the Raman and Scanning Electron Microscopy Facilities of the (C) Antiquity Publications Ltd, 2019 


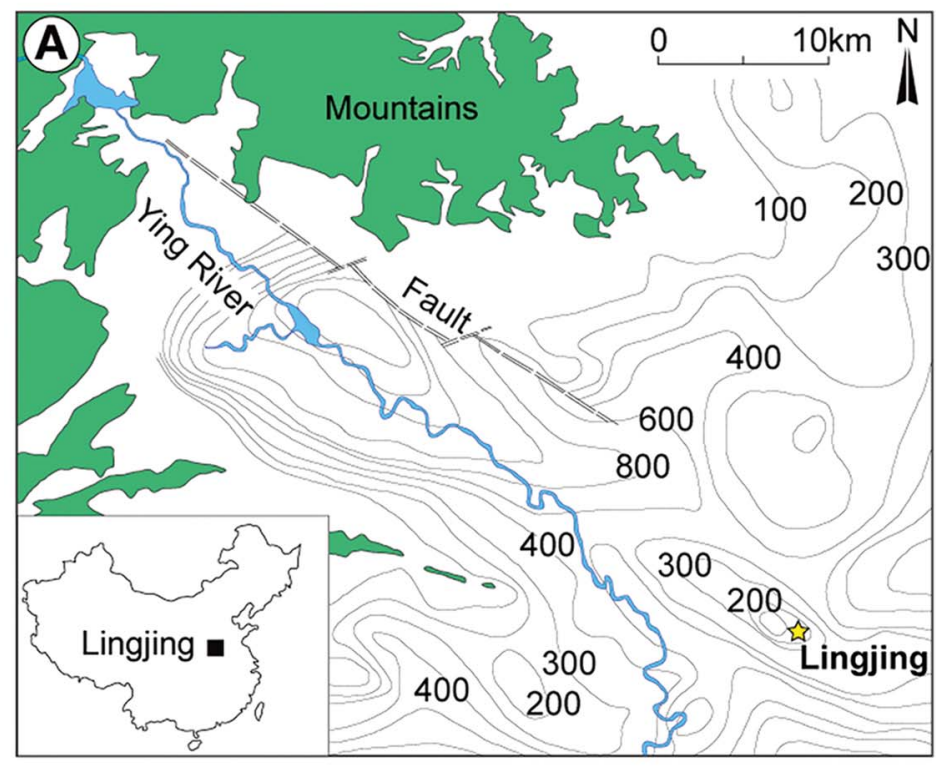

( $m$ above sea level)

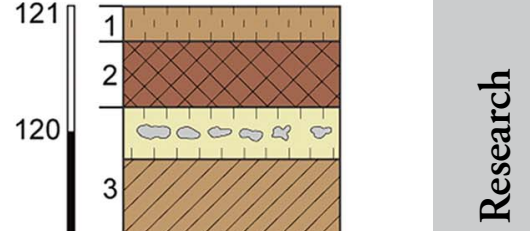

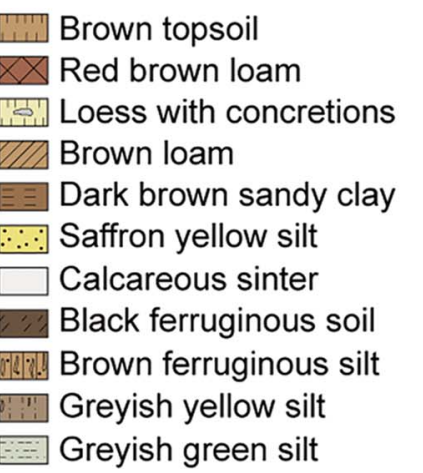

(4) Microlith tool industry

( Bird carving

$\bigoplus$ Animal fossils

(2) Stone artefacts

(1) Human fossils

$\square$ Location of OSL samples

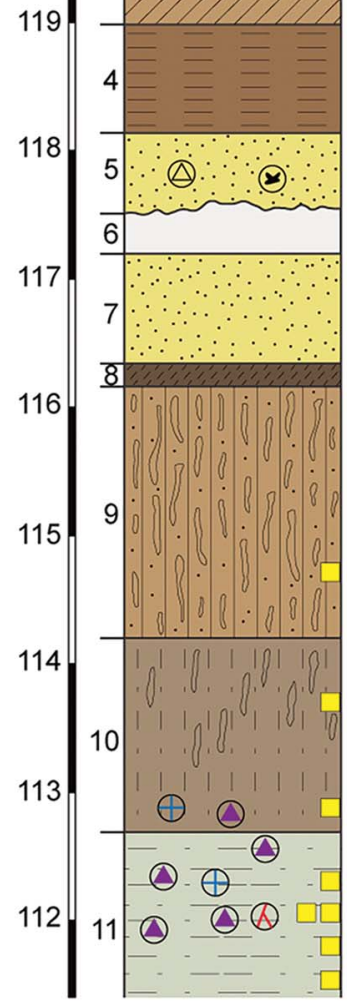

Figure 1. A) Location of Lingjing (Henan Province, China); B) stratigraphy indicating the geological and cultural layers (after Doyon et al. 2018).

Shandong University's Institute of Measurement and Testing. The specimens were examined visually, and then photographed with Canon PowerShot 100 and Nikon D300 AF Micro Nikkor $60 \mathrm{~mm}$ f/2.8D cameras. Microscopic analysis was conducted using a Leica Wild M3C stereomicroscope equipped with a Nikon CoolPix 900 digital camera at magnifications ranging from 4-40×. Data on the morphology and features of the engraved lines were recorded, along with the presence of a red residue. Identification of the cause of the modifications on the bone's surface is based on criteria inferred from the experimental reproduction and subsequent microscopic analysis of sequential marks produced on bone using different tools and motions (d'Errico 1995; Fritz 1999).

A total of 227 bone fragments from the 2005-2015 excavations exhibiting few or no concretions were examined microscopically. The following variables were recorded for those

(C) Antiquity Publications Ltd, 2019 
specimens that exhibit indisputable cut marks (Noe-Nygaard 1987; Lyman 1994; Fisher 1995; Fernández-Jalvo \& Andrews 2016): number, arrangement (divergent, overlapping, parallel or sub-parallel), morphology (curved, sinuous or straight), edge morphology (clean or fringed), and the occurrence of side striations, conspicuous changes in direction, surface micro-breaks and the presence of red residue.

A selected area of the engraved part of specimen 9L0141 was replicated using Coltene President regular body dental elastomer (Coltène, Switzerland). The negative replica was analysed with a Sensofar S-Neox confocal microscope driven by the SensoScan 6 software (Sensofar, Barcelona). The data was processed with SensoMap 7.3 software. Specimen 9L0141 and a sample of sediment from the cancellous bone were analysed with SEM-EDS and Raman spectroscopy. Sediment from layer 11 was analysed with ED-XRF (for details, see OSM 3).

\section{Results}

\section{Taphonomic analysis}

The surfaces of the analysed faunal remains are, when not affected by taphonomic processes or coated by concretions, exceptionally well preserved. Cut marks are the main anthropogenic modification observed on the faunal assemblage (23.79 per cent; Figure 2; OSM 4). They are present on all skeletal elements, including ribs (12.96 per cent). They show morphological traits typical of cut marks on fresh bone (Fisher 1995) and very rare changes in direction (OSM 4). Root etching affects 22.03 per cent of the analysed sample, while gnawing and etching resulting from consumption by carnivores affect 3.96 and 2.20 per cent of the sample, respectively. Other modifications include percussion marks possibly associated with marrow extraction (3.52 per cent), traces of use as retouchers (3.08 per cent) and staining produced by heat (1.32 per cent). Other than on specimen 9L0141, no red residues were detected on the 227 sampled faunal bone fragments.

\section{Microscopic analysis}

Although specimen 9L0141 is too fragmentary to propose a firm taxonomic attribution based on morphology (Figure 3), the thickness and flatness of the cortical bone and the morphology of the cancellous bone suggest that 9L0141 is the distal portion of an adult, large-sized mammal rib. The periosteal surface is pronounced and fibrous, comprising natural, alternating sub-parallel grooves and ridges (OSM 6). The four broken edges are ancient, as indicated by their colour and the slight smoothing of their surfaces under the microscope. The morphology of the broken edges and orientation indicate that they occurred on weathered bone (Villa \& Mahieu 1991; Lyman 1994). Seven sub-parallel lines cross the periosteal surface (Figure 4A). The abrupt terminations of L1 and L2, and the lower terminations of L3-5 indicate that they were interrupted by the adjacent fractures (Figure 5A; OSM 6). The upper terminations of L3-5 were engraved after the piece had already fragmented (OSM 6). L6 and L7 are complete and uninterrupted. The grainy appearance of the surface of all of the lines (Figure 6), their micro-fringed outlines, and the step micro-fractures produced when incising (C) Antiquity Publications Ltd, 2019 

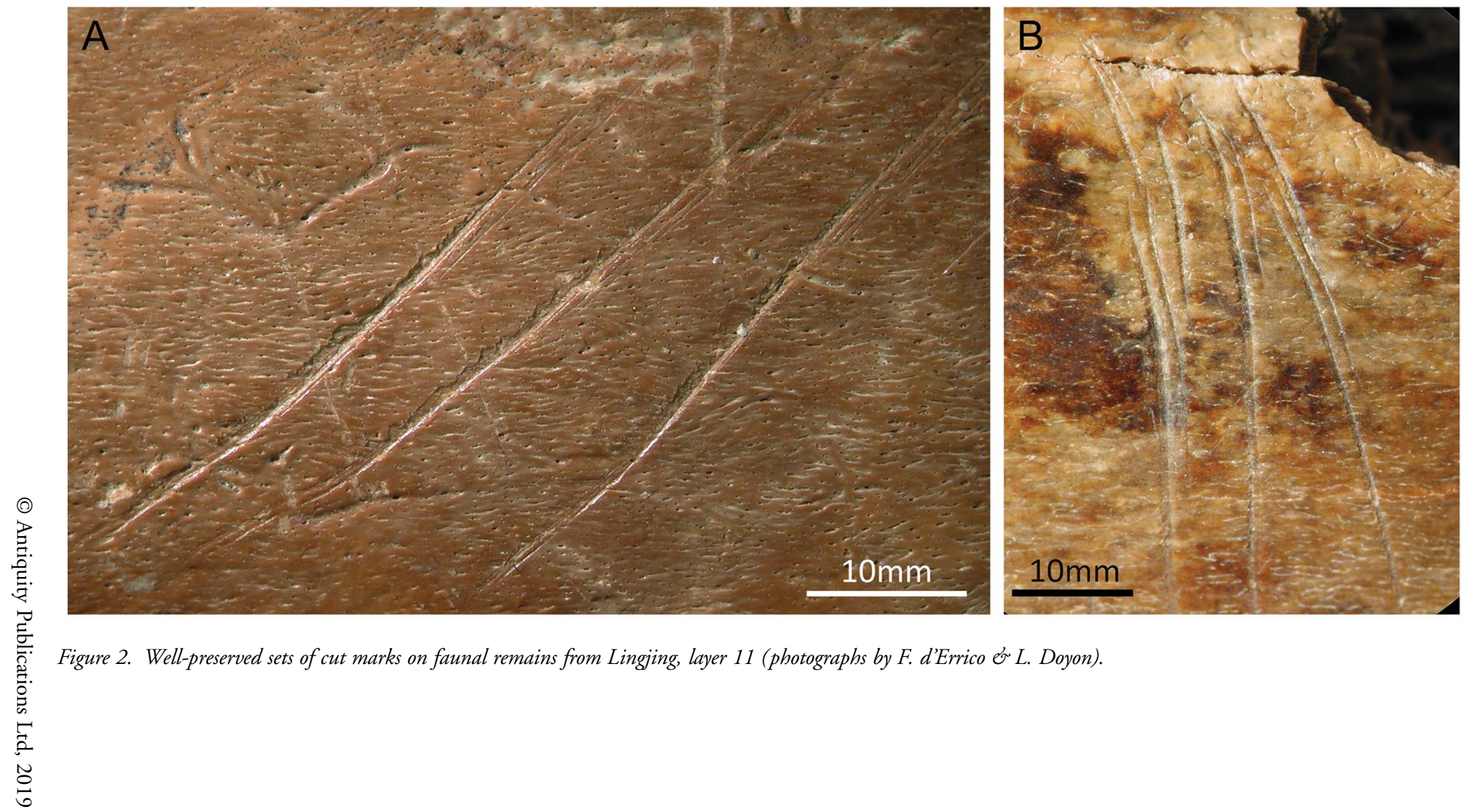

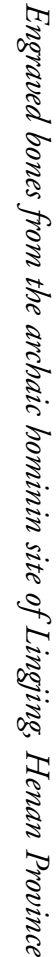

Figure 2. Well-preserved sets of cut marks on faunal remains from Lingiing, layer 11 (photographs by F. d'Errico \& L. Doyon).

Research 


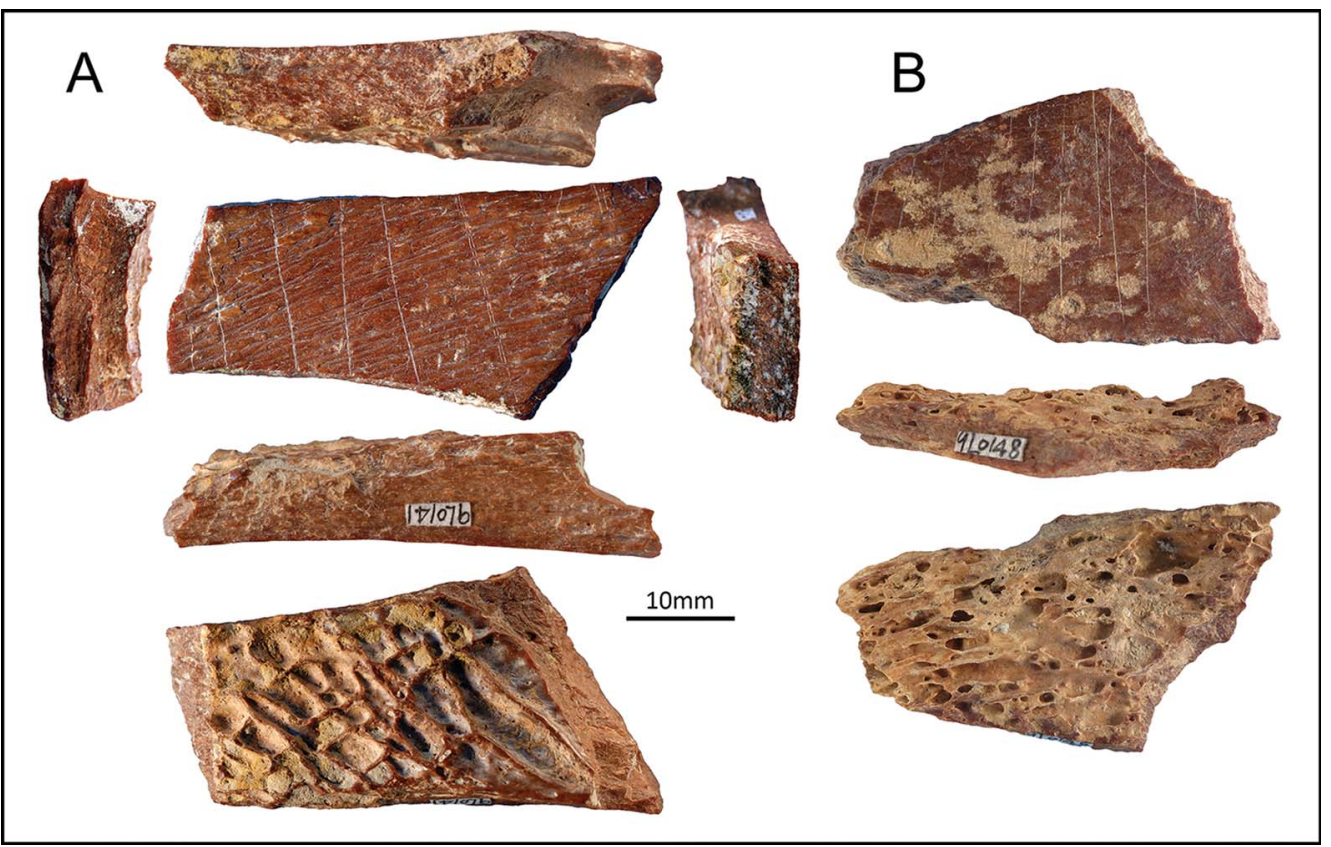

Figure 3. Photographs of the engraved specimens: A) 9L0141; B) 9 L0148 (photographs by F. d'Errico \& L. Doyon).

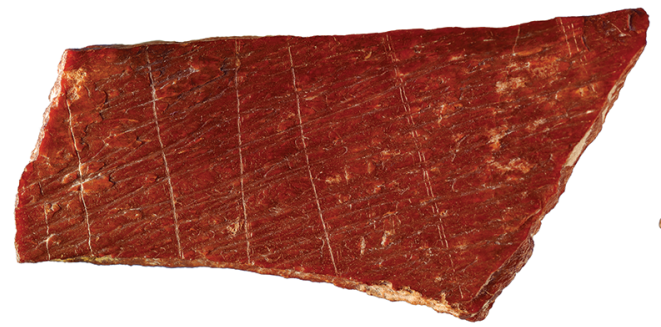

A

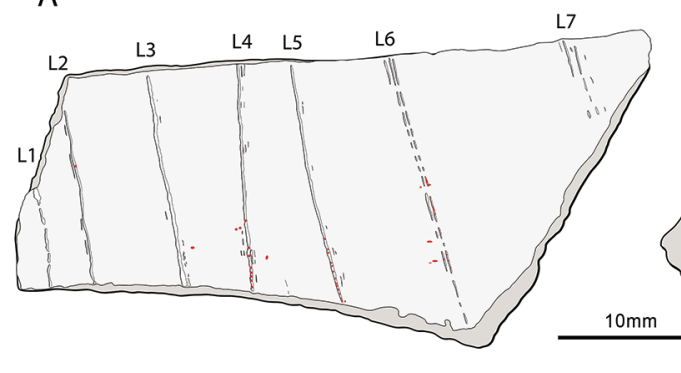

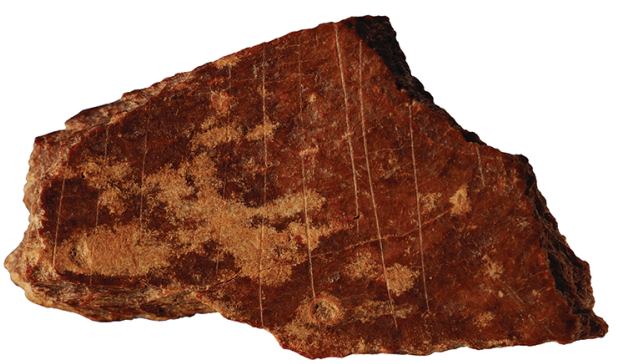

B

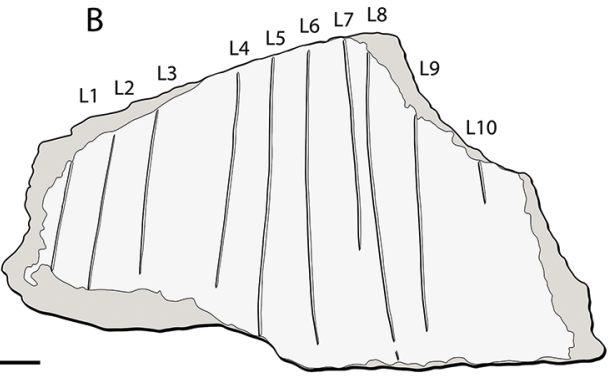

Figure 4. Photographs and tracing of the engraving on specimens: A) $9 L 0141$ (red dots indicate the location of red residues); B) 9 LO148 (photographs by F. d'Errico \& L. Doyon).

(C) Antiquity Publications Ltd, 2019 


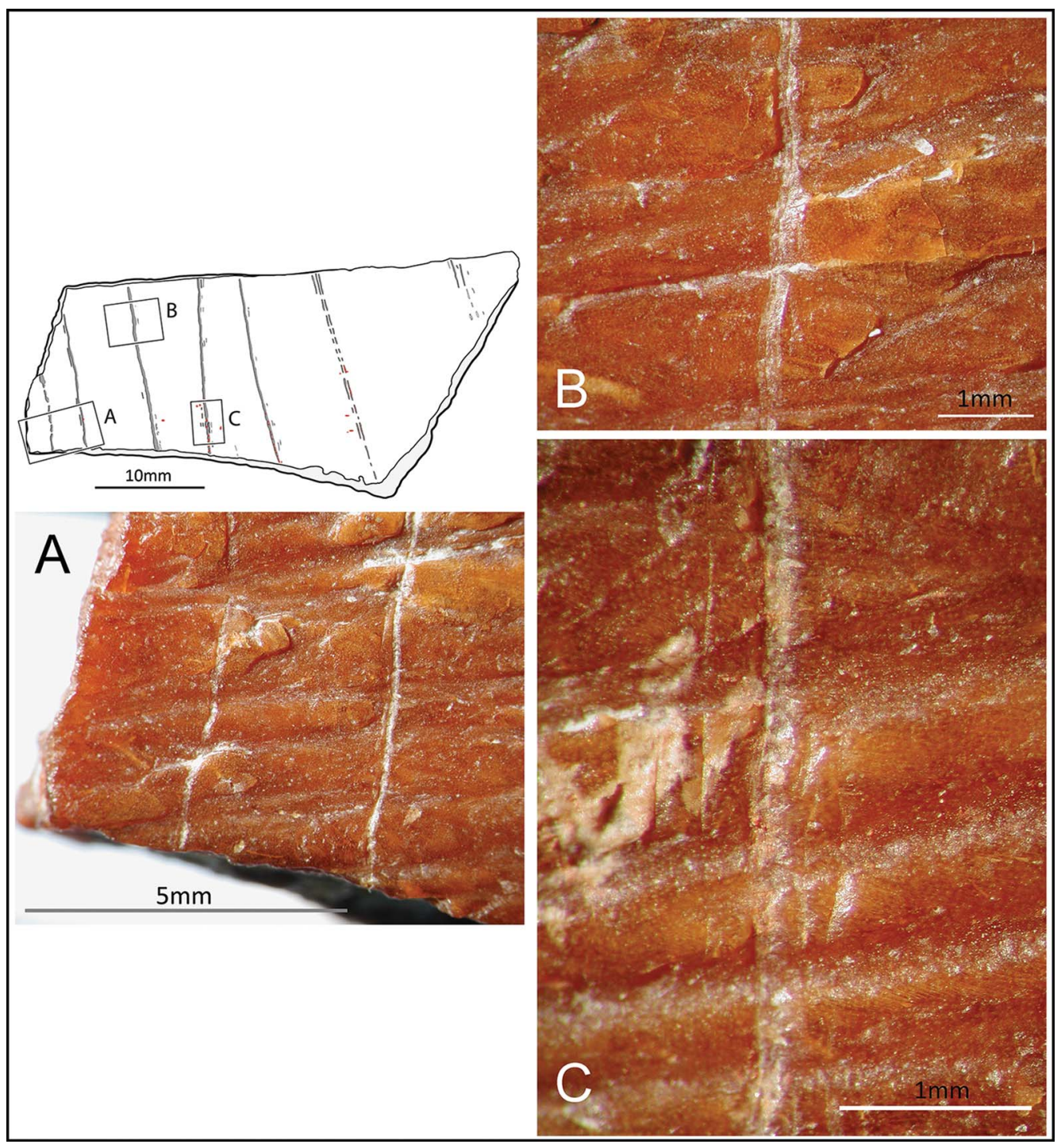

Figure 5. Microscopic photographs of engraved lines on specimen 9L0141. Changes in direction of lines crossing the fibrous structure of the bone indicate the use of a sharp point $(A-B)$. Red residues are present inside the engraved lines (C) (photographs by F. d'Errico \& L. Doyon).

through the natural ridges of the bone surface (see OSM 6), all suggest that they were engraved on weathered rather than fresh bone (OSM 5).

The depths of L1-5 remain constant when crossing the micro-grooves and ridges of the fibrous periosteal surface (Figure 5A-B), analysis of which shows that the grooves vary between 50 and $100 \mu \mathrm{m}$ in depth and between 100 and $600 \mu \mathrm{m}$ in width (OSM 6). Evidently, the tool tip was extremely sharp and no more than $50-100 \mu \mathrm{m}$ in width. The frequent, sudden changes in direction of L1-6 (Figure 5B-C) suggest instances of the momentary loss of control in the engraver's motion, due to tool speed changes when crossing the natural

(C) Antiquity Publications Ltd, 2019 


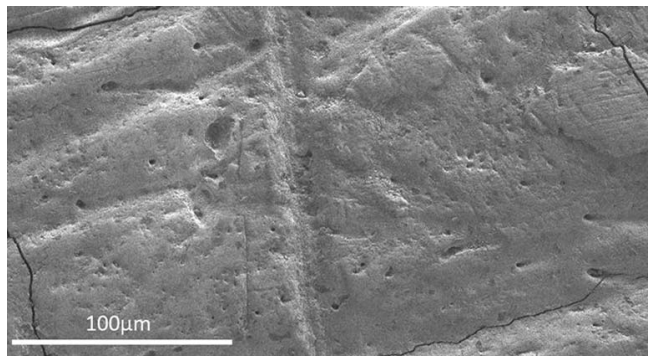

Figure 6. SEM photograph of specimen $9 L 0141$ showing the grainy, slightly eroded appearance of L4 (photographs by H. Li, Q. Wang \& Z. Zhang).

undulations of the bone's surface (d'Errico 1994, 1995). L1-5 were each engraved by a single passage of the tool. L6-7 comprise, respectively, three and five close, parallel and discontinuous striations each produced by a single passage of the point (OSM 6).

Similarities in section and width indicate that L1-2 were engraved by the same point, which created a narrow groove with a flat bottom (Figure 5A). L3-5 were also produced by the same point, which generated a wider and shallower groove with internal striations similar to each other, and sidestriations on both sides of the main line. The multiple striations that comprise L6-7 were probably made by the same tool that was used to engrave L3-5, although the former is more superficial (OSM 6). The morphological differences between L1-2 and L3-7 can either be attributed to a tool change, or to the wear or breakage of the point used to engrave L1-2. The location of the micro-fractures on the periosteal ridges indicates that the lines were engraved from the longer to the shorter edge of the bone (Figure 5A; OSM 7). The sections of well-defined lines are asymmetrical to the right (see OSM 5), which, considering the motion of direction, indicates a right-handed engraver (Bosinski et al. 2002; d'Errico et al. 2018). Right-handed engravers generally create sequences of parallel lines by juxtaposing them from left to right (d'Errico 1992). This would favour the interpretation that the morphological differences between L1-2 and L3-7 are the result of wear or breakage of the engraving tool.

Specimen 9L0148 is a rib fragment from an adult, large-sized mammal (Figure 3B). The flat periosteal surface displays areas of chemical etching (whitening) (Figure 7A), removal of primary bone lamellae and parallel sets of thin striations, which are attributable to trampling. The top, bottom and left broken edges are eroded and fringed; those on the right side are fresher, suggesting that the fragment experienced at least two distinct breakage events. Ten sub-parallel lines (L1-10), produced before breakage of the rib (see OSM 5), cross the periosteal surface (Figure 4B). Their narrowness, similar internal morphology and the absence of side striations demonstrate that they were engraved using the same sharp lithic point, in a single session (Figure 7B). Slight changes in direction when crossing natural micro-fractures and taphonomically damaged areas, along with their irregular outline, suggest that the lines were engraved on weathered bone. They were cut using a quick motion towards the wider edge of the object, as indicated by the narrow terminations of L6-10.

\section{Residue analysis}

Abundant red residues were observed microscopically on specimen 9L0141 within lines L2 and L4-6, and adjacent to lines L3-6 (Figure 4A; OSM 7). The whitish sediment from layer 11 , which was trapped in the specimen's cancellous bone, showed no such evidence of residue (see OSM 7). Raman analysis of the red residues from within the lines produced a composite spectrum with seven peaks at 225, 293, 411, 497, 612, 1242 and $1271 \mathrm{~cm}^{-1}$ (see OSM 7).

(C) Antiquity Publications Ltd, 2019 


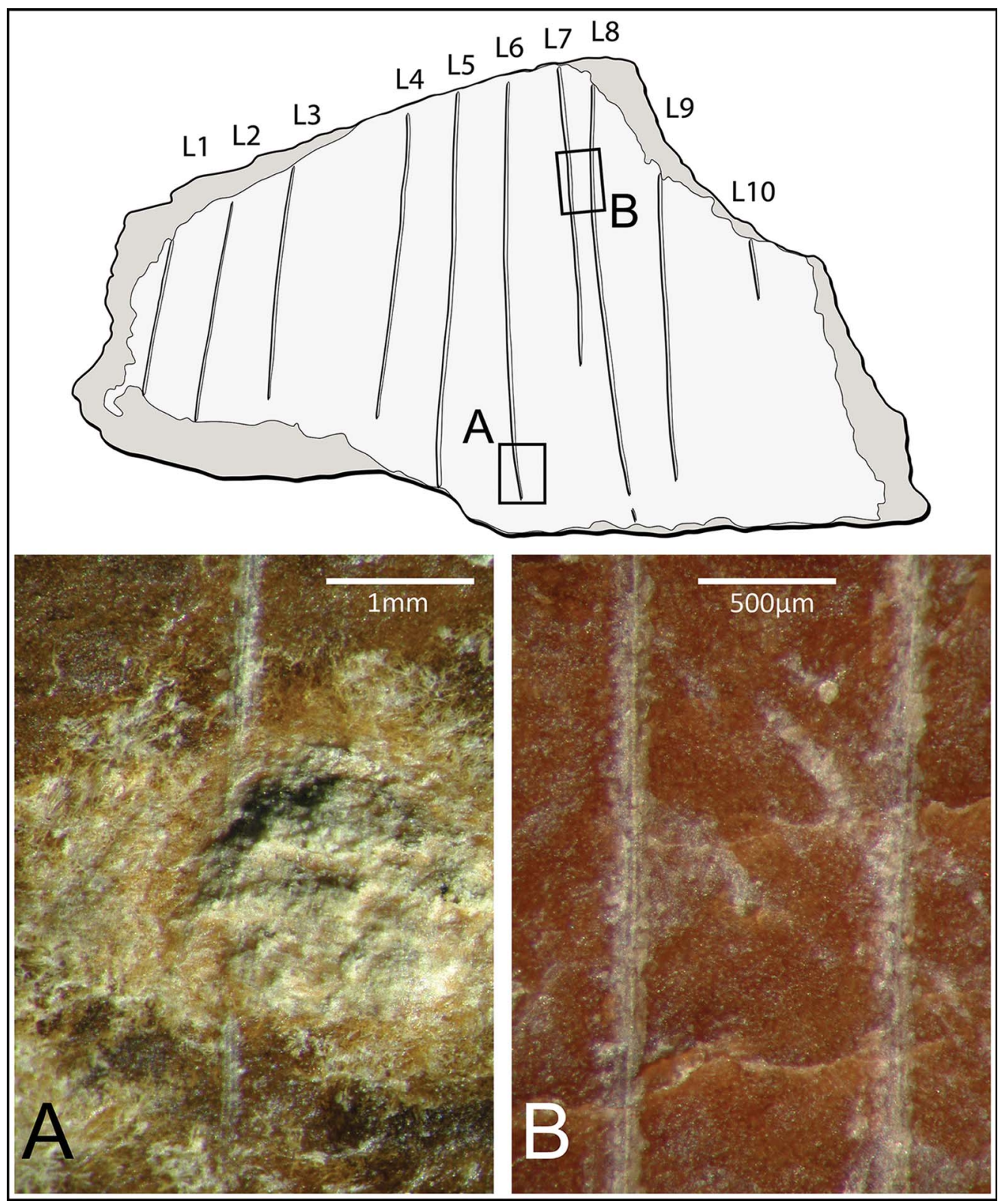

Figure 7. Close-up views of L6, L7 and L8 on specimen 9L0148: A) chemical etching affecting the bone's surface subsequent to the engraving; B) similar internal morphology indicating the use of the same tool (photographs by F. d'Errico \& L. Doyon).

The five peak values in the low frequencies identify the residue as haematite (de Faria $e$ t al. 1997). Raman analysis of the sediment from the cancellous bone identified only quartz and a single instance of a particle containing haematite (see OSM 7). SEM-EDS analysis reveals that the sediment comprises particles ranging from $20-200 \mu \mathrm{m}$ in size, and is mainly composed of mica — either muscovite or biotite—embedded in a clay matrix, which also contains

(C) Antiquity Publications Ltd, 2019 
small quantities of iron $(\mathrm{Fe})$, magnesium $(\mathrm{Mg})$ and calcium $(\mathrm{Ca})$. Single instances of quartz grain, zircon, bone fragment and an iron-rich particle are also detected (see OSM 7). ED-XRF analysis of sediment from layer 11 confirms that silicon $(\mathrm{Si})$ is the predominant chemical element, followed by aluminium (Al) and potassium (K); iron $(\mathrm{Fe})$ accounts only for 2.4-2.6 per cent (see OSM 7).

\section{Discussion and conclusion}

The lines on bone specimens 9L0141 and 9L0148 cannot result from excavation, cleaning or curation of the faunal assemblage. They differ in a number of respects from the lines exhibited on cut-marked bones from within layer 11. Cut marks on the latter generally display microscopic features consistent with cuts made on fresh bone. Generally, sets of close cut marks made in rapid succession on fresh bone by the same cutting edge rarely exceed four cuts, and they usually slightly diverge from a focal point, keeping a similar outline. In contrast, the lines on the two specimens - particularly on 9L0141 — were made on partially weathered fragments; several lines on this specimen were engraved when the bone was already fragmented. The lines on 9L0141 were produced by an extremely sharp point, and the prehistoric individual was particularly careful when engraving the first five lines, given the rugged topography of the periosteal surface. To increase the visibility of the subsequent lines (L6-7), the engraver marked them using multiple strokes. Combined, this evidence does not support an interpretation of the lines as evidence of butchery activity on 9L0141, but rather, deliberate engraving of the bone. Although less striking, the lines on 9L0148 still differ from fresh cut marks on faunal remains from the same layer in their number, morphology and in the tool used to produce them. Furthermore, damage to some of the lines by chemical alteration of the periosteal surface indicates that they are of ancient origin, attributable to neither excavation nor curation.

The numerous haematite-rich residues identified within four lines on 9L0141 and the virtual absence of iron-rich particles in the clay sediment of layer 11 is puzzling. Considering the chemical composition of layer 11, one would have expected to find white residue composed of clay and micas at the bottom of the engraved lines. The absence of white sediment and the presence instead of haematite-rich deposits in the lines and nearby recessed areas could be explained by the smearing of ochre powder on the bone surface to highlight the engraved pattern and increase its visibility-a common practice in Upper Palaeolithic mobiliary art (Buisson et al. 1989; García et al. 2016). The use of ochre to modify the appearance of personal ornaments is attested at $80 \mathrm{ka}$ BP from Middle Stone Age Moroccan sites, such as Taforalt, Rhafas and Ifri n'Ammar (d'Errico et al. 2009). The earliest evidence for the use of ochre in China comes from Zhoukoudian Upper Cave and Shuidonggou localities 2 and 8, in the form of modified ochre lumps and ornaments coloured with ochre (Pitarch Martí et al. 2017).

A growing body of evidence from Europe and Southeast Asia (Table 1; OSM 1) supports the hypothesis that the cultural adaptations of archaic hominins involved symbolically mediated behaviour, thereby challenging the notion that modern cognitive abilities are restricted to Homo sapiens. While many scholars now agree on this hypothesis with regard to Neanderthals, the present article offers the first evidence to suggest that the same may

(C) Antiquity Publications Ltd, 2019 
also apply to Denisovans - the probable creators of the engravings described here. The Lingjing engravings represent the first possible example of such behaviour in Eastern Asia to predate 40 kya. Results were obtained by combining contextual and taphonomic data, with detailed analyses of the objects. The deliberate nature of the markings on 9L0141-and probably on 9L0148 - as well as the application of ochre on the former appear to confirm the intentional character of these practices, and is fully consistent with the hypothesis that meaning may have been attributed to the patterns, to the moment in which the action took place, or to the action itself.

We are still far from understanding the meaning of these engravings for the archaic human groups living in China during the early Late Pleistocene. Doyon et al.'s (2018, 2019) recent identification of bone and antler fragments from layer 11 at Lingjing that were used to retouch lithics demonstrates that the Lingjing hominins were familiar with the mechanical properties of weathered bone and considered it to be a suitable raw material for producing artefacts. The Linging engravings suggest that these populations also saw bone as a medium on which they could permanently record sequential markings and use ochre as a substance to help highlight them. Future research may identify spatiotemporal consistencies that could offer clues to help in fully evaluating the significance of these behaviours.

\section{Supplementary material}

To view supplementary material for this article, please visit https:/doi.org/10.15184/aqy. 2019.81

\section{Acknowledgements}

We wish to thank Alain Queffelec (CNRS_UMR5199 PACEA) and François-Xavier Le Bourdonnec (CNRSUMR5060 IRAMAT-CRP2A) for their help with the sediment analyses. The scientific research at Lingjing is funded by grants from the National Natural Science Foundation of China $(41630102,41672020)$ and Shandong University 111 Project (111-2-09). The present study was funded by the Sino-French Cai Yuanpei programme (36707NF). This work was partially supported by the Research Council of Norway through its Centre's of Excellence funding scheme, SFF Centre for Early Sapiens Behaviour (SapienCE), project number 262618. L.H. acknowledges the support from the Strategic Priority Research Program of the Chinese Academy of Sciences, and the Chinese Academy of Sciences Pioneer Hundred Talents Program. L.D. was granted financial support from the China/Shandong University International Postdoctoral Exchange Program, and the Institut écologie et environnement of the Centre National de la Recherche Scientifique (CNRS-InEE). PACEA (UMR5199 CNRS) is a partner team of the Labex LaScArBx-ANR n ${ }^{\circ}$ ANR-10-LABX-52.

\section{References}

Bednarik, R.G. 1994. The Pleistocene art of Asia. Journal of World Prehistory 8: 351-75. https://doi.org/10.1007/BF02221090

Bednarik, R.G. \& Y. You. 1991. Palaeolithic art from China. Rock Art Research 8: 119-23.

Benazzi, S., K. Douka, C. Fornai, C.C. Bauer, O. Kullmer, J. Svoboda, I. Pap, F. Mallegni, P. Bayle, M. Coquerelle, S. Condemi,
A. Ronchitelli, K. Harvati \& G.W. Weber. 2011. Early dispersal of modern humans in Europe and implications for Neanderthal behaviour. Nature 479: 525-28. https://doi.org/10.1038/nature10617

Bosinski, G., F. D’Errico \& P. Schiller. 2002. Die gravierten Frauendarstellungen von Gönnersdorf. Stuttgart: Franz Steiner.

Bruner, E. 2014. Functional craniology, human evolution, and anatomical constraints in the

(C) Antiquity Publications Ltd, 2019 
Neanderthal braincase, in T. Akazawa,

N. Ogihara, H.C. Tanabe \& H. Terashima (ed.)

Dynamics of learning in Neanderthals and modern humans, volume 2: 121-29. Tokyo: Springer. https://doi.org/10.1007/978-4-431-54553-8_13

Buisson, D., M. Menu, G. Pinçon \& P. Walter. 1989. Les objets colorés du Paléolithique supérieur: cas de la grotte de La Vache (Ariège). Bulletin de la Société préhistorique française 86: 183-91.

Chen, T., R.E.M. Hedges \& Z. Yuan. 1992. New AMS ${ }^{14} \mathrm{C}$ dating on Upper Cave and relative issues. Acta Anthropologica Sinica 11: 112-15.

D'Errico, F. 1992. Technology, motion, and the meaning of Epipaleolithic art. Current Anthropology 33: 94-109. https://doi.org/10.1086/204039

- 1994. L'art gravé azilien: de la technique à la signification. Paris: CNRS Éditions.

- 1995. Image analysis and 3-D optical surface profiling of Upper Palaeolithic mobiliary art. Microscopy and analysis 51: 27-29.

D'Errico, F. \& C.B. Stringer. 2011. Evolution, revolution or saltation scenario for the emergence of modern cultures? Philosophical Transactions of the Royal Society B: Biological Sciences 366: 106069. https://doi.org/10.1098/rstb.2010.0340

d’Errico, F., M. Vanhaeren, N. Barton, A. Bouzouggar, H. Mienis, D. Richter, J.-J. Hublin, S.P. McPherron \& P. Lozouet. 2009. Additional evidence on the use of personal ornaments in the Middle Paleolithic of North Africa. Proceedings of the National Academy of Sciences of the USA 106: 16051-56. https://doi.org/10.1073/pnas.0903532106

D'ERrico, F., R.G. Moreno \& R.F. Rifkin. 2012. Technological, elemental and colorimetric analysis of an engraved ochre fragment from the Middle Stone Age levels of Klasies River Cave 1, South Africa. Journal of Archaeological Science 39: 942-52. https://doi.org/10.1016/j.jas.2011.10.032

d’Errico, F., L. Doyon, I. Colagé, A. Queffelec, E. Le Vraux, G. Giacobini, B. Vandermeersch $\&$ B. Maureille. 2018. From number sense to number symbols: an archaeological perspective. Philosophical Transactions of the Royal Society B: Biological Sciences 373: 20160518. https://doi.org/10.1098/rstb.2016.0518

DE BOER, B. 2012. Loss of air sacs improved hominin speech abilities. Journal of Human Evolution 62: $1-6$.

https://doi.org/10.1016/j.jhevol.2011.07.007 de Faria, D.L.A., S. Venâncio Silva \& M.T. de Oliveira. 1997. Raman microspectroscopy of some iron oxides and oxyhydroxides. Journal of Raman Spectroscopy 28: 873-78. https://doi.org/10.1002/(SICI) 1097-4555 (199711)28:11<873::AID-JRS177>3.0.CO;2-B

Doyon, L., Z. Li, H. Li \& F. D’Errico. 2018. Discovery of circa 115 000-year-old bone retouchers at Lingjing, Henan, China. PLoS ONE 13: e0194318. https://doi.org/10.1371/journal.pone.0194318

Doyon, L., H. Li, Z. LI, H. WANG \& Q. ZhaO. 2019. Further evidence of organic soft hammer percussion and pressure retouch from Lingjing (Xuchang, Henan, China). Lithic Technology 44: $100-17$.

https://doi.org/10.1080/01977261.2019. 1589926

Fernández-Jalvo, Y. \& P. Andrews. 2016. Atlas of taphonomic identifications. New York: Springer. https://doi.org/10.1007/978-94-017-7432-1

Finlayson, C., K. Brown, R. Blasco, J. Rosell, J.J. Negro, G.R. Bortolotti, G. Finlayson, A. Sánchez Marco, F. Giles Pacheco, J. Rodríguez Vidal, J.S. Carrión, D.A. Fa \& J.M. Rodríguez Llanes. 2012. Birds of a feather: Neanderthal exploitation of raptors and corvids. PLoS ONE 7: e45927.

https://doi.org/10.1371/journal.pone.0045927

FisHeR, J.W. 1995. Bone surface modifications in zooarchaeology. Journal of Archaeological Method and Theory 2: 7-68.

https://doi.org/10.1007/BF02228434

FriTz, C. 1999. Towards the reconstruction of Magdalenian artistic techniques: the contribution of microscopic analysis of mobiliary art. Cambridge Archaeological Journal 9: 189-208. https://doi.org/10.1017/S0959774300015377

García, C.R., V.V. Bonilla, I.R. Marín \& S.M. Mascarós. 2016. A unique collection of Palaeolithic painted portable art: characterization of red and yellow pigments from the Parpalló Cave (Spain). PLoS ONE 11: e0163565. https://doi.org/10.1371/journal.pone.0163565

Grün, R., J.S. Brink, N.A. Spooner, L. Taylor, C.B. Stringer, R.G. Franciscus \& A.S. Murray. 1996. Direct dating of Florisbad hominid. Nature 382: 500-501. https://doi.org/10.1038/382500a0

Gunz, P., S. Neubauer, B. Maureille \& J.-J. Hublin. 2010. Brain development after

(C) Antiquity Publications Ltd, 2019 
birth differs between Neanderthals and modern humans. Current Biology 20: 921-22. https://doi.org/10.1016/j.cub.2010.10.018

Haynes, G. 1991. Mammoths, mastodonts, and elephants: biology, behavior and the fossil record. Cambridge: Cambridge University Press.

Henshilwood, C.S., F. D’Errico \& I. Watts. 2009. Engraved ochres from the Middle Stone Age levels at Blombos Cave, South Africa. Journal of Human Evolution 57: 27-47. https://doi.org/10.1016/j.jhevol.2009.01.005

Hofmann, D.L., C.D. Standish, M. García-Diez, P.B. Pettitt, J.A. Milton, J. Zilhão, J.J. Alcolea-González, P. Cantalejo-Duarte, H. Collado, R. de Balbín, M. Lorblanchet, J. Ramos-Muñoz, G.-C. Weniger \& A.W.G. Pike. 2018. U-Th dating of carbonate crusts reveals Neandertal origin of Iberian cave art. Science 359: 912-15. https://doi.org/10.1126/science.aap7778

Hovers, E. \& A. Belfer-Cohen. 2006. 'Now you see it, now you don' 't': modern human behavior in the Middle Paleolithic, in E. Hovers \& S.L. Kuhn (ed.) Transitions before the transition: 295-304. Boston (MA): Springer.

Hublin, J.-J., A. Ben-Ncer, S.E. Bailey, S.E. Freiduine, S. Neubauer, M.M. Skinner, I. Bergmann, A. Le Cabec, S. Benazzi, K. Harvati \& P. Gunz. 2017. New fossils from Jebel Irhoud, Morocco and the pan-African origin of Homo sapiens. Nature 546: 289-92. https://doi.org/10.1038/nature22336

JunkeR, T. 2010. Art as a biological adaptation, or: why modern humans replaced the Neanderthals. Quartär 57: 171-78.

Li, H., Z. Li, X. GaO, K. Kuman \& A. Sumner. 2019. Technological behavior of the early Late Pleistocene archaic humans at Lingjing (Xuchang, China). Archaeological and Anthropological Science. https://doi.org/10.1007/s12520-018-0759-7

LI, Z. 2007. A primary study on the stone artifacts of Lingjing site excavated in 2005. Acta Anthropologica Sinica 26: 138-54.

LI, Z. \& W. Dong. 2007. Mammalian fauna from the Lingjing Paleolithic site in Xuchang, Henan Province. Acta Anthropologica Sinica 26: 345-60.

Li, Z., X. Wu, L. Zhou, W. Liu, X. Gao, X. Nian \& E. Trinkaus. 2017. Late Pleistocene archaic human crania from Xuchang, China. Science 355: 969-72. https://doi.org/10.1126/science.aal2482

Lieberman, P. 2007. The evolution of human speech: its anatomical and neural bases. Current Anthropology 48: 39-66. https://doi.org/10.1086/509092

Lyman, R.L. 1994. Vertebrate taphonomy. New York: Cambridge University Press. https://doi.org/10.1017/CBO9781139878302

Martinón-Torres, M., X. Wu, J.M. Bermúdez de Castro, S. Xing \& W. Liu. 2017. Homo sapiens in the Eastern Asian Late Pleistocene. Current Anthropology 58(S17): 434-48. https://doi.org/10.1086/694449

Mellars, P. 2010. Neanderthal symbolism and ornament manufacture: the bursting of a bubble? Proceedings of the National Academy of Sciences of the USA 107: 20147-48. https://doi.org/10.1073/pnas.1014588107

Müller, W. \& C. PASDA. 2011. Site formation and faunal remains of the Middle Pleistocene site Bilzingsleben. Quartär 58: 25-49.

Neubauer, S. 2015. Human brain evolution: ontogeny and phylogeny, in E. Bruner (ed.) Human paleoneurology: 95-120. Cham: Springer.

Nian, X.M., L.P. Zhou \& J.T. Qin. 2009. Comparisons of equivalent dose values obtained with different protocols using a lacustrine sediment sample from Xuchang, China. Radiation Measurements 44: 512-16. https://doi.org/10.1016/j.radmeas.2009.06.002

Noe-NygaArd, N. 1987. Taphonomy in archaeology with special emphasis on man as a biasing factor. Journal of Danish Archaeology 6: 7-62. https://doi.org/10.1080/0108464X.1987. 10589975

Norton, C.J. \& J.J.H. Jin. 2009. The evolution of modern human behavior in East Asia: current perspectives. Evolutionary Anthropology 18: 247-60. https://doi.org/10.1002/evan.20235

Nowell, A. 2010. Defining behavioral modernity in the context of Neandertal and anatomically modern human populations. Annual Review of Anthropology 39: 437-52. https://doi.org/10.1146/annurev.anthro. 012809.105113

Pearce, E., C. Stringer \& R.I.M. Dunbar. 2013. New insights into differences in brain organization between Neanderthals and 
anatomically modern humans. Proceedings of the Royal Society of London B: Biological Sciences 280: 20130168.

https://doi.org/10.1098/rspb.2013.0168

PEI, W.C. 1934. A preliminary report on the Late

Palaeolithic cave of Choukoutien. Acta Geologica Sinica 13: 327-58.

Peng, F., X. GaO, H. Wang, F. Chen, D. Liu \&

S. Pei. 2012. An engraved artifact from

Shuidonggou, an early Late Paleolithic site in northwest China. Chinese Science Bulletin 57: 4594-99.

https://doi.org/10.1007/s11434-012-5317-6

Peresani, M., I. Fiore, M. Gala, M. Romandini \&

A. Tagliacozzo. 2011. Late Neandertals and the intentional removal of feathers as evidenced from bird bone taphonomy at Fumane Cave 44 ky B.P., Italy. Proceedings of the National Academy of Sciences of the USA 108: 3888-93. https://doi.org/10.1073/pnas.1016212108

Petтiтt, P. 2002. The Neanderthal dead: exploring mortuary variability in Middle Palaeolithic Eurasia. Before Farming 2002(4): 1-26. https://doi.org/10.3828/bfarm.2002.1.4

Pitarch Martí, A., Y. Wei, X. Gao, F. Chen \& F. D'ERrico. 2017. The earliest evidence of coloured ornaments in China: the ochred ostrich eggshell beads from Shuidonggou Locality 2 . Journal of Anthropological Archaeology 48: 102 13. https://doi.org/10.1016/j.jaa.2017.07.002

Radovčić, D., A.O. SRšEn, J. Radovčić \& D.W. Frayer. 2015. Evidence for Neandertal jewellery: modified white-tailed eagle claws at Krapina. PLoS ONE 10: e0119802. https://doi.org/10.1371/journal.pone.0119802

RodríGuez-VIDAL, J. et al. 2014. A rock engraving made by Neanderthals in Gibraltar. Proceedings of the National Academy of Sciences of the USA 111: 13301-306.

https://doi.org/10.1073/pnas.1411529111

Romandini, M., M. Peresani, V. Laroulandie, L. Metz, A. Pastoors, M. Vaquero \& L. Slimak. 2014. Convergent evidence of eagle talons used by late Neanderthals in Europe: a further assessment on symbolism. PLoS ONE 9: e101278.

https://doi.org/10.1371/journal.pone.0101278

Spoor, F., J.-J. Hublin, M. Braun \&

F. ZonNEveld. 2003. The bony labyrinth of
Neanderthals. Journal of Human Evolution 44: 141-65. https://doi.org/10.1016/S0047-2484(02)00166-5

STRINGer, C. 2016. The origin and evolution of Homo sapiens. Philosophical Transactions of the Royal Society B: Biological Sciences 371: 20150237. https://doi.org/10.1098/rstb.2015.0237

Villa, P. \& F. D'Errico. 2001. Bone and ivory points in the Lower and Middle Paleolithic of Europe. Journal of Human Evolution 41: 69-112. https://doi.org/10.1006/jhev.2001.0479

Villa, P. \& E. Mahieu. 1991. Breakage patterns of human long bones. Journal of Human Evolution 21: $27-48$. https://doi.org/10.1016/0047-2484(91)90034-S

Villa, P. \& W. Roebroeks. 2014. Neandertal demise: an archaeological analysis of the modern human superiority complex. PLoS ONE 9: e96424. https://doi.org/10.1371/journal.pone.0096424

Vincent, A. 1988. L'os comme artefact au Paléolithique moyen: principes d'étude et premiers résultats, in M. Otte, L. Binford \& J.P. Rigaud (ed.) L'homme de Néandertal 4, la technique: 185-96. Liège: ERAUL.

Watts, I. 2010. The pigments from Pinnacle Point Cave 13B, Western Cape, South Africa. Journal of Human Evolution 59: 392-411. https://doi.org/10.1016/j.jhevol.2010.07.006

You, Y.Z. 1984. Preliminary study of a Palaeolithic bone engraving. Kexue Tongbao 29: 80-82.

Zhang, S., Z. LI, Y. Zhang \& X. GaO. 2012. Skeletal element distributions of the large herbivores from the Lingjing site, Henan Province, China. Science China: Earth Sciences 55: 246-53. https://doi.org/10.1007/s11430-011-4279-x

ZILHÂO, J. 2011. Aliens from outer time? Why the 'human revolution' is wrong, and where do we go from here?, in S. Condemi \& G.-C. Weniger (ed.) Continuity and discontinuity in the peopling of Europe: 331-66. Dordrecht: Springer.

ZiLHão, J. et al. 2010. Symbolic use of marine shells and mineral pigments by Iberian Neandertals. Proceedings of the National Academy of Sciences of the USA 107: 1023-28.

https://doi.org/10.1073/pnas.0914088107

Received: 14 June 2018; Revised: 28 September 2018; Accepted: 6 November 2018

(C) Antiquity Publications Ltd, 2019 